Advance Journal of Food Science and Technology 14(6): 194-201, 2018

DOI:10.19026/ajfst.14.5981

ISSN: 2042-4868; e-ISSN: 2042-4876

(C) 2018 Maxwell Scientific Publication Corp.

Submitted: July 27, $2018 \quad$ Accepted: September 7, 2018

Published: October 25, 2018

\title{
Research Article \\ Pumpkin Peel Flour Extracts Obtained by an Ultrasound-Assisted System as a Rich Source of Bioactive Compounds with Antioxidant Properties
}

\author{
${ }^{1}$ Suelen Ávila, ${ }^{2}$ Vivian Cristina Ito, ${ }^{1}$ Gerson Lopes Teixeira, ${ }^{3}$ Flávia Roberta Buss Marenda, ${ }^{2}$ Juliane \\ Souza, ${ }^{4}$ Acácio Antonio Ferreira Zielinski and ${ }^{1}$ Rosemary Hoffmann Ribani \\ ${ }^{1}$ Graduate Program in Food Engineering, Federal University of Paraná, \\ Polytechnic Center, 81531-980, Curitiba, \\ ${ }^{2}$ Graduate Program in Food Science and Technology, State University of Ponta Grossa, \\ 84030-900, Ponta Grossa, \\ ${ }^{3}$ Graduate Program in Food Science, Federal University of Santa Catarina, 88034-001, Florianópolis, \\ ${ }^{4}$ Graduate Program in Chemical Engineering and Food Engineering, Federal University of Santa Catarina, \\ 88034-001, Florianópolis, Brazil
}

\begin{abstract}
This study evaluated an Ultrasound-Assisted solid-liquid Extraction (UAE) aided by Response Surface Methodology (RSM) to obtain bioactive-rich extracts from pumpkin (Cucurbita moschata) dried peel. Total Phenolic Compounds (TPC), Total Flavonoids Content (TFC), as well as the in vitro Antioxidant Activity (AA), were assessed. The physicochemical analysis revealed that Pumpkin Peel Flour (PPF) has an excellent nutritional profile, comprised by lipids $(11.80 \%)$, proteins $(6.02 \%)$ and total fibre $(1.96 \%)$, in addition to valuable quantity of minerals such as $\mathrm{P}, \mathrm{Mg}, \mathrm{Ca}, \mathrm{Fe}, \mathrm{Na}, \mathrm{Zn}$ and $\mathrm{Mn}$. A Box-Behnken design was applied to analyse the effect of the concentration of solvent, the extraction time and the solid-liquid ratio as independent variables and the TPC, TFC and AA in response. PPF is a rich source of TPC (145.51-479.05 mg GAE/L) and TFC (44.08-89.68 mg CTE/L), which contribute to a high antioxidant activity $(653.90-1698.20 \mu \mathrm{mol} \mathrm{TE} / \mathrm{L})$. Using the RSM, a simultaneous optimisation was performed by the desirability function and the optimum condition to maximise the obtaining of target compounds was with $80 \%$ ethanol in the proportion of $10 \mathrm{~mL} / \mathrm{g}$ (solvent vs raw material) during $45 \mathrm{~min}$. External validation was subsequently conducted on the proposed optimal point and all results were within $\pm 95 \%$ of the prediction intervals proposed by the models. Thus, the UAE aided by RSM was shown to be an adequate approach to model the recovery of bioactive compounds with antioxidant properties from a by-product of the pumpkin industry.
\end{abstract}

Keywords: Antioxidant capacity, box-behnken design, by-products, composition, Cucurbita moschata, desirability function

\section{INTRODUCTION}

Pumpkin from America has varieties which are classified into Cucurbita maxima, Cucurbita pepo, Cucurbita moschata and Cucurbita mixta. The peel is a source of carotene, pectin, minerals, vitamins and other compounds beneficial to the human health (de Carvalho et al., 2012). There is a wide diversity of applications for pumpkin and it is also essential to valorise its residues regarding the development of products, which contributes to maximising available resources while reducing problems related to environmental impact (Shi et al., 2013).

Cucurbita moschata has received considerable attention in recent years due to the nutritional and health benefits of its bioactive compounds used for nutritional enrichment in functional foods, as well as the oil obtained from its seeds and fruits (Abou-Elella and Mourad, 2015; Rezig et al., 2012). The function of natural antioxidants, which are found in many compounds classified as secondary plant metabolites in the form of polyphenols (phenolic acids and flavonoids) and terpenoids (carotenoids), is to protect the living tissues against damage caused by oxidative stress and they are directly related in prevention of various diseases (Krishnaiah et al., 2011; Sarikurkcu et al., 2009).

Extraction processes comprise the fundamental methods in the phytochemical recovery of antioxidants from plant by-products because its objective is to

\footnotetext{
Corresponding Author: Suelen Ávila, Federal University of Paraná, Graduate Program in Food Engineering, Polytechnic Center, 81531-980-Curitiba-PR- Brazil, Tel.: +55-41-33613232
}

This work is licensed under a Creative Commons Attribution 4.0 International License (URL: http://creativecommons.org/licenses/by/4.0/). 
release these composites from the structures in which they are found (González-Montelongo et al., 2010). The different conventional methods mostly employed for the extraction of bioactive compounds, including phenolics, are Soxhlet extraction, maceration and hydrodistillation (Azmir et al., 2013). These conventional procedures are now being replaced or modified as a result of the advent of alternative techniques, such as the ultrasound system (Maran et al., 2013, 2017) which can provide optimised extraction conditions in short periods of time, improving the removal of bioactive compounds. Some of these methods are related to 'green' or sustainable, according to the EPA (the United States Environmental Protection Agency), which means that they use less harmful chemicals and renewable raw materials. Furthermore, they are more energy efficient and use less derived compounds, among other advantages (Azmir et al., 2013).

There is a little number of studies in the literature regarding the extraction of bioactive components from pumpkin using Response Surface Methodology (RSM) and they are focused on the extraction of phenolic compounds from pulp (Altemimi et al., 2016), polysaccharides from peel by ultrasound (Maran et al., 2013) and assisted by microwave (Zheng et al., 2011; Koštálová et al., 2016). As we are aware, no study regarding maximising the level of extracted polyphenols and antioxidant activity of Cucurbita moschata peel was found in the literature. Thus, in this study, we present the assessment of an ultrasoundassisted extraction aided by RSM to obtain bioactiverich extracts from pumpkin peel and evaluation of the total phenolic compounds, total flavonoids content and in vitro antioxidant capacity.

\section{MATERIALS AND METHODS}

Chemicals and sample collection: Fresh pumpkin peel with pulp residue was obtained from "Q-Sabor", a company specialised in confectionery in the city of Ponta Grossa (Paraná, Brazil). All solvents and chemicals utilised in this study were of analytical grade.

Processing of pumpkin peel: The peel from the fresh pumpkins was manually removed from the pulp, cut into pieces of about $3 \mathrm{~cm}^{2}$ and subjected to drying $\left(65^{\circ} \mathrm{C}\right)$ in a circulation oven and hot air renewal (MA 035 model, Marconi, São Paulo Brazil). The sample was then ground and sieved using 60 mesh (particle size up to $250 \mu \mathrm{m}$ ) to obtain the pumpkin peel flour (PPF, Fig. 1). A quantity of $750 \mathrm{~g}$ of raw peel resulted in $500 \mathrm{~g}$ of pumpkin peel flour $(66.67 \%$ yield $)$. This flour was stored in airtight containers and kept underrefrigeration until further analysis.

Physicochemical analysis: The contents of moisture, protein, ash, lipids and total dietary fibre of the PPF were determined according to AOAC (2008). For the mineral analysis which included calcium $(\mathrm{Ca})$, copper $(\mathrm{Cu})$, cobalt $(\mathrm{Co})$, iron $(\mathrm{Fe})$, magnesium $(\mathrm{Mg})$, potassium $(\mathrm{K})$, sodium $(\mathrm{Na})$, zinc $(\mathrm{Zn})$ and manganese $(\mathrm{Mn})$ the readings were taken with the aid of a flame atomic absorption spectrometer (Varian, model 240FS), using as an accessory an automatic SIPS diluter system equipped with deuterium lamp as background correction and multi-element hollow cathode lamps.

For the pectin extraction, it was used boiling nitric acid solution $(55 \mathrm{mmol})$ which was added on the rawmaterial in a solid-liquid ratio of $1: 25(\mathrm{w} / \mathrm{v})$, maintained for $10 \mathrm{~min}$. The extract was filtered in synthetic fabric, cooled to $25 \pm 2{ }^{\circ} \mathrm{C}$ and added ethanol $(1: 2 \mathrm{v} / \mathrm{v})$ at room temperature $(30 \mathrm{~min})$ (Fertonani et al., 2009). The pectin was dried in an oven with air circulation $\left(40^{\circ} \mathrm{C}\right)$ until constant weight. The yield was determined by the ratio between the mass of the dry pectin and the mass of PPF multiplied by $100(\%)$.

Bioactive compounds and in vitro antioxidant activity analysis: Total Phenolic Compounds (TPC) were assessed using the Folin-Ciocalteu reagent and the results expressed as milligrams of gallic acid equivalents per litre (mg GAE/L) (Singleton and Rossi, 1965). The Total Flavonoid Content (TFC) was expressed as milligrams of catechin equivalents per litre (mg CTE/L) (Zhishen et al., 1999). The in vitro Antioxidant Activity (AA) was performed by the FRAP assay as described by Benzie and Strain (1996) and expressed in $\mu \mathrm{mol}$ of Trolox equivalents per litre $(\mu \mathrm{mol}$ $\mathrm{TE} / \mathrm{L})$.

Optimisation of extraction of phenolic compounds by UAE: In order to optimise the conditions for the recovery of phenolic compounds from the PPF, a BoxBehnken design with 15 combinations and three repetitions of the central point. The following factors (independent variables) were studied: ethanol

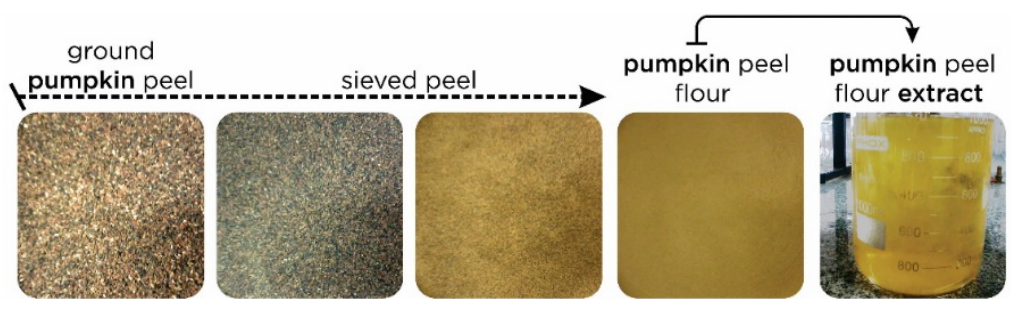

Fig. 1: Pumpkin peel flour and the extract obtained by the ultrasound-assisted system 
Adv. J. Food Sci. Technol., 14(6): 194-201, 2018

Table 1: Total phenolic compounds (TPC), total flavonoids content (TFC) and antioxidant activity (FRAP) in the extracts made with the ethanol solution

\begin{tabular}{|c|c|c|c|c|c|c|}
\hline Run & $\begin{array}{l}\text { Ethanol } \\
(\%)\left(X_{1}\right)\end{array}$ & $\begin{array}{l}\text { Proportion of sample } \times \text { solvent } \\
\left(\mathrm{mL}^{\prime} \mathrm{g}\right)\left(\mathrm{X}_{2}\right)\end{array}$ & Time $(\min )\left(X_{3}\right)$ & TPC (mg GAE/L) & $\mathrm{TFC}(\mathrm{mg} \mathrm{CTE} / \mathrm{L})$ & FRAP $(\mu \mathrm{mol} \mathrm{TE} / \mathrm{L})$ \\
\hline 1 & 50 & 20 & 30 & $291.33 \pm 25.46^{\mathrm{c}}$ & $61.20 \pm 2.50^{\text {def }}$ & $855.50 \pm 246.98^{\text {cde }}$ \\
\hline 2 & 50 & 20 & 30 & $284.54 \pm 29.41^{\mathrm{cd}}$ & $57.71 \pm 4.82^{\mathrm{efg}}$ & $904.30 \pm 182.84^{\text {cde }}$ \\
\hline 3 & 50 & 20 & 30 & $288.34 \pm 22.06^{\mathrm{c}}$ & $56.80 \pm 1.39^{\mathrm{efg}}$ & $789.90 \pm 81.2^{\mathrm{de}}$ \\
\hline 4 & 50 & 10 & 15 & $437.32 \pm 36.05^{\mathrm{ab}}$ & $81.65 \pm 5.48^{\mathrm{ab}}$ & $1811.90 \pm 283.74^{\mathrm{a}}$ \\
\hline 5 & 50 & 10 & 45 & $409.00 \pm 46.05^{\mathrm{b}}$ & $77.41 \pm 3.94^{\mathrm{bc}}$ & $1638.30 \pm 136.7^{\mathrm{a}}$ \\
\hline 6 & 50 & 30 & 15 & $219.26 \pm 30.62^{\mathrm{e}}$ & $47.71 \pm 2.50^{\mathrm{hi}}$ & $661.90 \pm 347.1^{\mathrm{e}}$ \\
\hline 7 & 50 & 30 & 45 & $196.38 \pm 24.23^{\text {ef }}$ & $44.08 \pm 3.53^{\mathrm{i}}$ & $683.40 \pm 328.03^{\mathrm{e}}$ \\
\hline 8 & 20 & 10 & 30 & $479.05 \pm 48.7^{\mathrm{ab}}$ & $69.38 \pm 2.66^{\mathrm{cd}}$ & $1622.80 \pm 161.97^{\mathrm{ab}}$ \\
\hline 9 & 20 & 30 & 30 & $206.91 \pm 24.50^{\mathrm{e}}$ & $51.95 \pm 2.53^{\text {ghi }}$ & $653.90 \pm 190.69^{\mathrm{e}}$ \\
\hline 10 & 20 & 20 & 15 & $293.56 \pm 39.97^{\mathrm{c}}$ & $62.26 \pm 3.09^{\mathrm{def}}$ & $1112.00 \pm 188.3^{\text {cd }}$ \\
\hline 11 & 20 & 20 & 45 & $296.15 \pm 30.45^{\mathrm{c}}$ & $59.83 \pm 2.89^{\mathrm{efg}}$ & $812.30 \pm 247.49^{\text {cde }}$ \\
\hline 12 & 80 & 10 & 30 & $395.61 \pm 60.41^{\mathrm{b}}$ & $89.68 \pm 11.76^{\mathrm{a}}$ & $1698.20 \pm 291.82^{\mathrm{a}}$ \\
\hline 13 & 80 & 20 & 15 & $177.47 \pm 32.81^{\text {ef }}$ & $53.92 \pm 9.36^{\mathrm{fgh}}$ & $778.40 \pm 281.2^{\mathrm{de}}$ \\
\hline 14 & 80 & 20 & 45 & $229.01 \pm 16.52^{\text {de }}$ & $71.35 \pm 1.72^{\mathrm{c}}$ & $1216.10 \pm 132.61^{\mathrm{bc}}$ \\
\hline 15 & 80 & 30 & 30 & $145.51 \pm 26.43^{\mathrm{f}}$ & $44.68 \pm 3.64^{\mathrm{i}}$ & $776.50 \pm 350.88^{\mathrm{de}}$ \\
\hline \multicolumn{4}{|c|}{$p$ (Normality) } & 0.060 & 0.161 & 0.052 \\
\hline \multicolumn{4}{|c|}{$p$ (Hartley) } & 0.976 & 0.203 & 0.945 \\
\hline \multicolumn{4}{|c|}{$p$ (ANOVA) } & $<0.0001$ & $<0.0001$ & $<0.0001$ \\
\hline
\end{tabular}

concentration $\left(\%, \mathrm{X}_{1}\right)$; solid-liquid ratio $\left(\mathrm{mL} / \mathrm{g}, \mathrm{X}_{2}\right)$; and time of extraction ( $\mathrm{min}, \mathrm{X}_{3}$ ), at three levels of variation (Table 1). The extractions were performed at a controlled temperature $\left(25^{\circ} \mathrm{C}\right)$ using an ultrasound device $(47 \mathrm{kHz}, 130 \mathrm{~W}$, Ultrasonic Cleaners, Vernon Hills, USA) equipped with a digital time controller, in airtight jars with the liquid part entirely submerged. After the extraction, the samples were submitted to centrifugation during $20 \mathrm{~min}$ at $3400 \mathrm{~g}$ and the supernatant was vacuum filtered through a $0.45 \mu \mathrm{m}$ Millipore membrane.

Statistical analysis: All the variables were tested for normality using the Shapiro-Wilk test and homogeneity of variances checked by Hartley test. The data followed a normal distribution with $p>0.05$. Differences between groups were evaluated by one-way ANOVA, followed by Fisher's test when discrimination was necessary between samples. A $p$-value $\leq 0.05$ was considered significant. RSM was used to model the recovery of TPC and the AA of the pumpkin peel. A second-order polynomial model was applied to analyse the experimental data. The generalised model used in the analysis of RSM is shown in Eq. (1):

$$
Y=\beta_{0}+\sum_{i=1}^{3} \beta i X i+\sum_{i=1}^{3} \beta i i X_{1}^{2}+\sum_{i=1}^{2} \sum_{j=i+1}^{3} \beta_{i j} X_{i} X_{j}
$$

where,

$$
\begin{array}{ll}
\mathrm{Y} & =\text { The predicted response } \\
\beta_{0} & =\text { Constant } \\
\beta_{\mathrm{i}}, \beta_{\mathrm{ii}} \text { and } \beta_{\mathrm{ij}}= & \text { The coefficients of linear, quadratic and } \\
& \text { interaction regression } \\
\text { Respectively } &
\end{array}
$$

$\mathrm{X}_{\mathrm{i}}$ and $\mathrm{X}_{\mathrm{j}}=$ The independent variables
The statistical significance of the terms in the regression equations was evaluated by ANOVA for each response. The terms with statistically insignificant results were excluded from the initial model and the experimental data were tested again only for the significant parameters $(p<0.05)$. After the models were built, a simultaneous optimisation to maximise the extraction of TPC, TFC and AA was obtained using the desirability function proposed by Derringer and Suich (1980). In order to check the predictive value of the models, by comparing the predictive values with the experimental data, experimental procedures were performed and the results were analysed using the prediction intervals at 95\%. The STATISTICA v. 13.2 software (StatSoft Inc., USA) was used to perform all the statistical analyses.

\section{RESULTS AND DISCUSSION}

Proximate composition of Pumpkin Peel Flour (PPF): The flour obtained from Cucurbita moschata showed $11.80 \pm 0.31 \%$ lipids, $8.20 \pm 0.13 \%$ moisture, $7.36 \pm 0.09 \%$ ash, $6.02 \pm 0.12 \%$ protein and $1.96 \pm 0.02 \%$ total dietary fibre. These values may vary depending on the part of the fruit that is used and how it is processed. Mirhosseini et al. (2015) studied the pumpkin flour from Malaysia and they obtained $1.17 \mathrm{~g} / 100 \mathrm{~g}$ lipids, $10.54 \mathrm{~g} / 100 \mathrm{~g}$ moisture, $6.01 \mathrm{~g} / 100 \mathrm{~g}$ ash and 9.63 $\mathrm{g} / 100 \mathrm{~g}$ protein, different from the results found in this study.

Potassium was the element found in the most significant quantity (223.47 $\mathrm{mg} / 100 \mathrm{~g}$ of PPF), followed by $24.93 \mathrm{mg}$ magnesium, $11.68 \mathrm{mg}$ calcium, $0.39 \mathrm{mg}$ iron, $0.38 \mathrm{mg}$ sodium, $0.23 \mathrm{mg}$ zinc and 0.10 mg manganese. Potassium was the highest mineral found by Ponka et al. (2015) in a study about pumpkin. According to Akwaowo et al. (2000), the evaluation of the mineral content of edible parts of pumpkin, as well 
as its non-conventionally edible parts, showed that parts such as seeds, roots and stems have significant concentrations of minerals which may be used for the enrichment of foods. Thus, the same could be assumed for the peel.

The pectin extracted from the raw pumpkin peel presented a yield of $3.1 \pm 0.83 \%$. Other works also evaluated the pectin extraction from pumpkin and they found a yield between 3.1 to $7.1 \%$ (Koštálová et al., 2016) and a yield of $14 \%$ (Ptichkina et al., 2008).

Bioactive compounds and antioxidant activity of pumpkin peel flour extracts: Pumpkin peel flour has an excellent potential for the extraction of phenolic compounds such as other by-products that have already been studied aiming to obtain bioactive-enriched extracts, including those from peanut skin (Elsorady and Ali, 2018), beer by-products (Barbosa-Pereira et al., 2014), wine by-products (Casazza et al., 2010), potato peels (Wu et al., 2012), olive oil (Rubio-Senent et al., 2013), jabuticaba peel (Santos and Meireles, 2011) and apple pomace flour (Ito et al., 2016).

The mean values for the extraction of phenolic compounds, flavonoids and antioxidant activity in PPF extracts are shown in Table 1. The mean values of the coordinates relating to the central point of the dependent variables in this experiment were: $288.07 \mathrm{mg}$ $\mathrm{GAE} / \mathrm{L}$ for phenolic compounds $(\mathrm{CV}=1.2 \%) ; 58.57$ $\mathrm{mg} \mathrm{CTE} / \mathrm{L}$ for total flavonoids $(\mathrm{CV}=4 \%)$ and 849.9 $\mu \mathrm{mol} \mathrm{TE} / \mathrm{L}(\mathrm{CV}=6.8 \%)$ for FRAP. The TPC from pumpkin peel extracts varied significantly $(p<0.05)$, from 145.41 to $479.05 \mathrm{mg} / \mathrm{L}$. The highest value for TPC was observed in experiment 8 under the following conditions: Concentration of $20 \%$ ethanol, in the proportion of $10 \mathrm{~mL} / \mathrm{g}$, for $30 \mathrm{~min}$. The model for the extraction of phenolics was significant $(p<0.001)$, but it showed a lack-of-fit $(p=0.017)$. However, the model that was built was able to explain $95.64 \%$ of total variance $\left(R_{\text {adj }}^{2}=0.9446\right)$.

Although the model presented a lack-of-fit, it can be considered proper to predict the content of phenolic compounds because the model generated by RSM presented a $p$-value lower than 0.05 and adjusted $\mathrm{R}^{2}>0.70$, thus it is possible to assume that the model had good predictive characteristics (Khajeh, 2011). The ethanol concentration $\left(\mathrm{X}_{1}\right)$ and the solid-liquid ratio $\left(\mathrm{X}_{2}\right)$ significantly decreased the recovery of TPC and the quadratic regression coefficient was significant and positive. The model that predicted the extraction of phenolic compounds is given in Eq. (2):

$$
\mathrm{TPC}=753.78-1.37 \mathrm{X}_{1}-30.05 \mathrm{X}_{2}+0.45 \mathrm{X}_{2}^{2}
$$

The response surface values and the predicted values compared with those that were observed, are shown in Fig. 2. The total flavonoids content ranged significantly, from 44.08 to $89.68 \mathrm{mg} / \mathrm{L}$, with experiment 12 providing the highest values under the following conditions: $80 \%$ ethanol, in the proportion of $10 \mathrm{~mL} / \mathrm{g}$, for $30 \mathrm{~min}$. The created model was significant $(p<0.001)$, showed no lack-of-fit $(p=0.12)$ and was able to explain $81.69 \%$ of the variance, presenting an adjusted $\mathrm{R}^{2}$ of 0.8028 . The solid-liquid ratio significantly decreased the extraction of total flavonoids. The model that predicted the extraction of total flavonoids is presented in Eq. (3):

$$
\mathrm{TFC}=94.39-1.62 \mathrm{X}_{2}
$$

The antioxidant activity measured by the FRAP method ranged from 653.90 to $1811.90 \mu \mathrm{mol} / \mathrm{L}$ and experiment 4 provided the highest AA under the following extraction conditions: $50 \%$ ethanol, at a ratio of 10 $\mathrm{mL} / \mathrm{g}$, for $15 \mathrm{~min}$. A model built to predict the antioxidant activity of the pumpkin peel extracts is shown in Eq. (4):

$$
\mathrm{FRAP}=3000.11-157.66 \mathrm{X}_{2}+2.69 \mathrm{X}_{2}^{2}
$$

This model was significant $(p<0.001)$, showed no lack of fit $(p=0.15)$ and was able to explain $91.56 \%$ of the variance of the data with an adjusted $\mathrm{R}^{2}$ of 0.9015 . The interaction between the ethanol concentration and time significantly increased the extraction of antioxidant activity. As in the other predictive models, the solid-liquid ratio was significant and negative.

Morelli and Prado (2012) optimised the parameters of solvent concentration, time and temperature for the extraction of TPC and AA of red grape jelly using an ultrasound-assisted system with a central rotating composite model using RSM. Within the evaluated parameters they found that the use of ultrasound was more efficient when compared to other methods and that RSM was excellent in determining the best combination of parameters. Using RSM and the same extraction parameters as for pumpkin peel, Sarkis et al. (2014) analysing a sesame seed 'cake' (a by-product of the oil industry) they confirmed that the second-order polynomial model provided a satisfactory description of most of the experimental data. These approaches can be applied in the development of industrial processes, thereby improving the efficiency of large-scale systems. Figure 3 shows the positive correlation coefficients between all the analyses. The content of TPC correlated with antioxidant capacity $(\mathrm{r}=0.87, p<0.001)$ and a significant correlation $(p<0.001)$ was found between the content of total flavonoids and antioxidant capacity $(\mathrm{r}=$ $0.92)$ and between TPC and TFC $(r=0.81)$. A study by John et al. (2014) found that the high content of phenolic compounds in Chukrasia tabularis $(17.2 \mathrm{mg}$ $\mathrm{GAE} / \mathrm{g}$ ) showed a linear correlation between phenolic content and antioxidant activity. The results of a study by Maizura et al. (2011) also demonstrated a positive correlation between TPC and FRAP assay of kesum, 

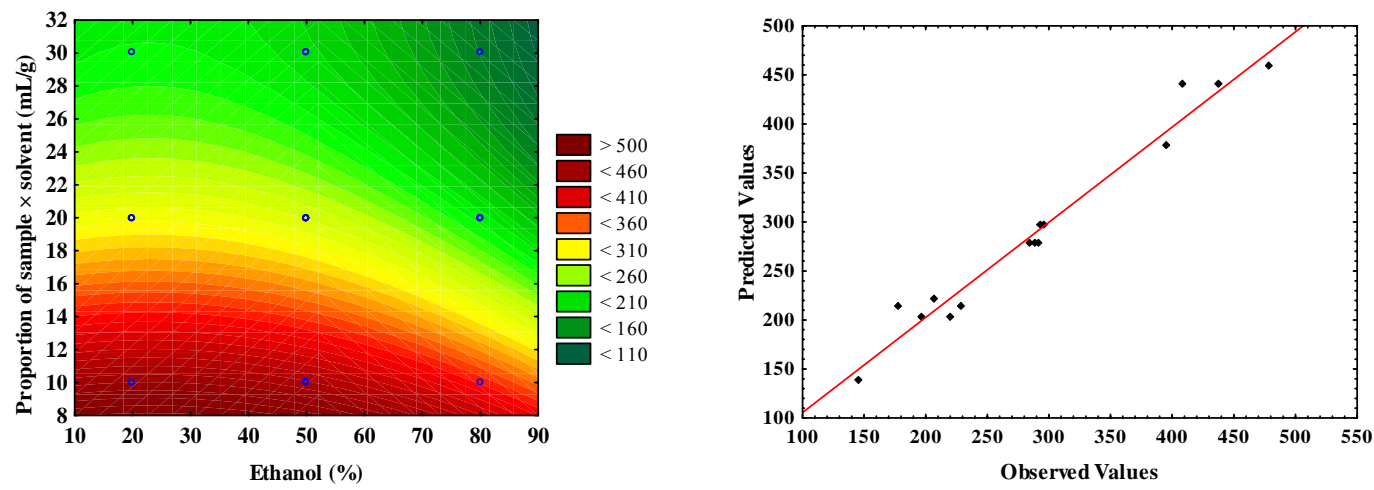

(a)
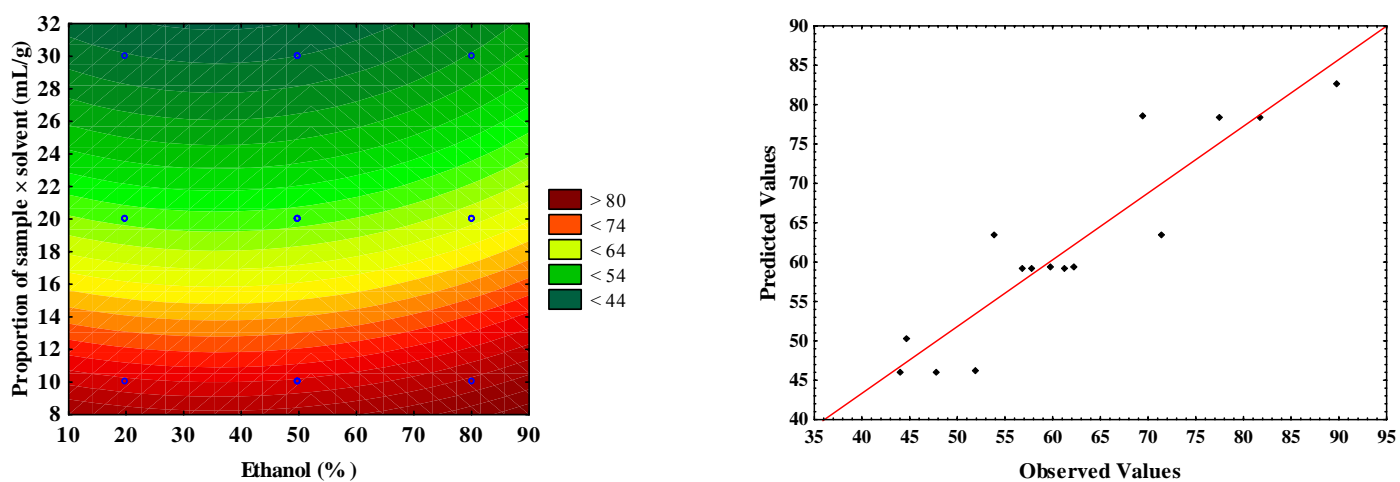

(b)
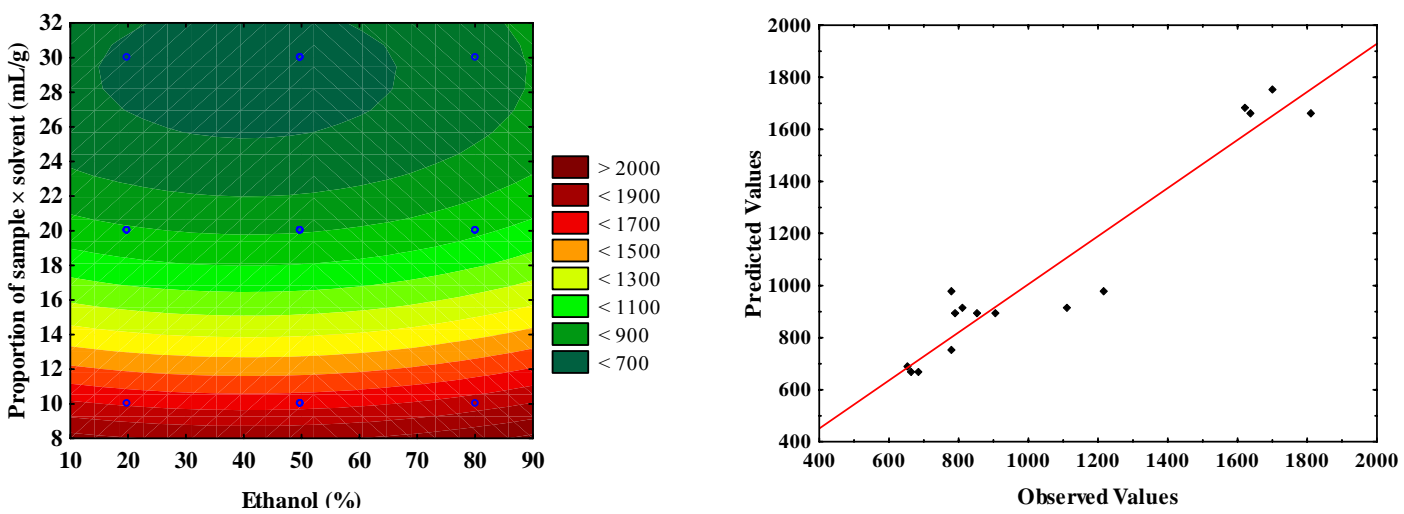

(c)

Fig. 2: Response surface and predicted values vs observed values of the proposed models for (a) total phenolic compounds, (b) total flavonoid content and (c) antioxidant activity measured by FRAP

ginger and turmeric extract $(r=0.91, p<0.01)$, demonstrating that phenolic compounds are the main contributors to antioxidant activity. Turumtay et al. (2014) studied tissues of Anzer tea and found a clear correlation $(r=0.93)$ between phenolic content and antioxidant activity. According to Chirinos et al. (2013), this same correlation also occurs in Andean plants in Peru.

Several studies have reported the content of phenolic compounds and antioxidant activity present in pumpkin seeds. However, researches involving pumpkin peel flour are still scarce. Pumpkin is considered as a healthy and functional plant because it is rich in $\alpha$-tocopherol, $\beta$-carotene, vitamin $A$, vitamin $\mathrm{C}$, phenols, flavonoids, amino acids and carbohydrates (Guiné et al., 2011). Some varieties, such as Cucurbita moschata, Cucurbita maxima and Cucurbita pepo, have colours ranging from bright yellow to orange and they reveal elevated levels of carotenoids, mainly $\alpha$ and $\beta$ carotene, $\beta$-cryptoxanthin, lutein and zeaxanthin (de 
(a)

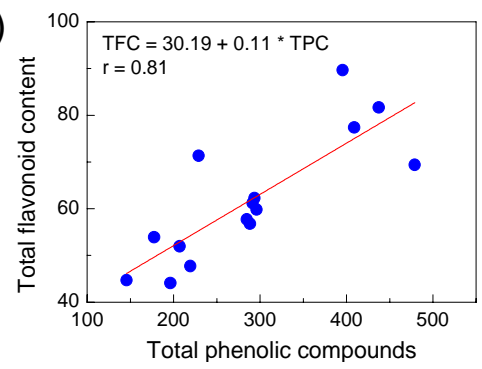

(b)

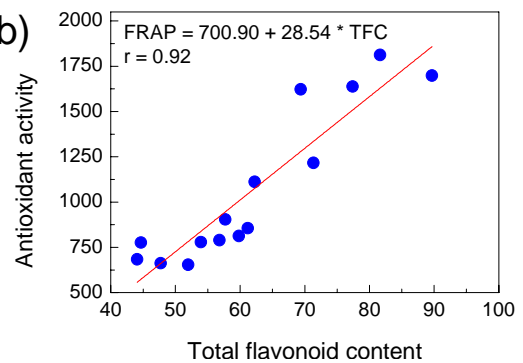

(c)

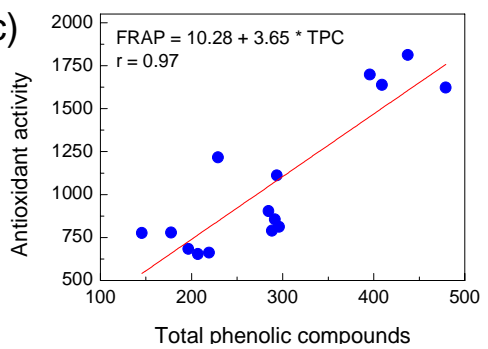

Fig. 3: Analysis of the correlation between the analyses; (a) TPC $\times$ FRAP, (b) TFC $\times$ FRAP, (c) TPC $\times$ TFC

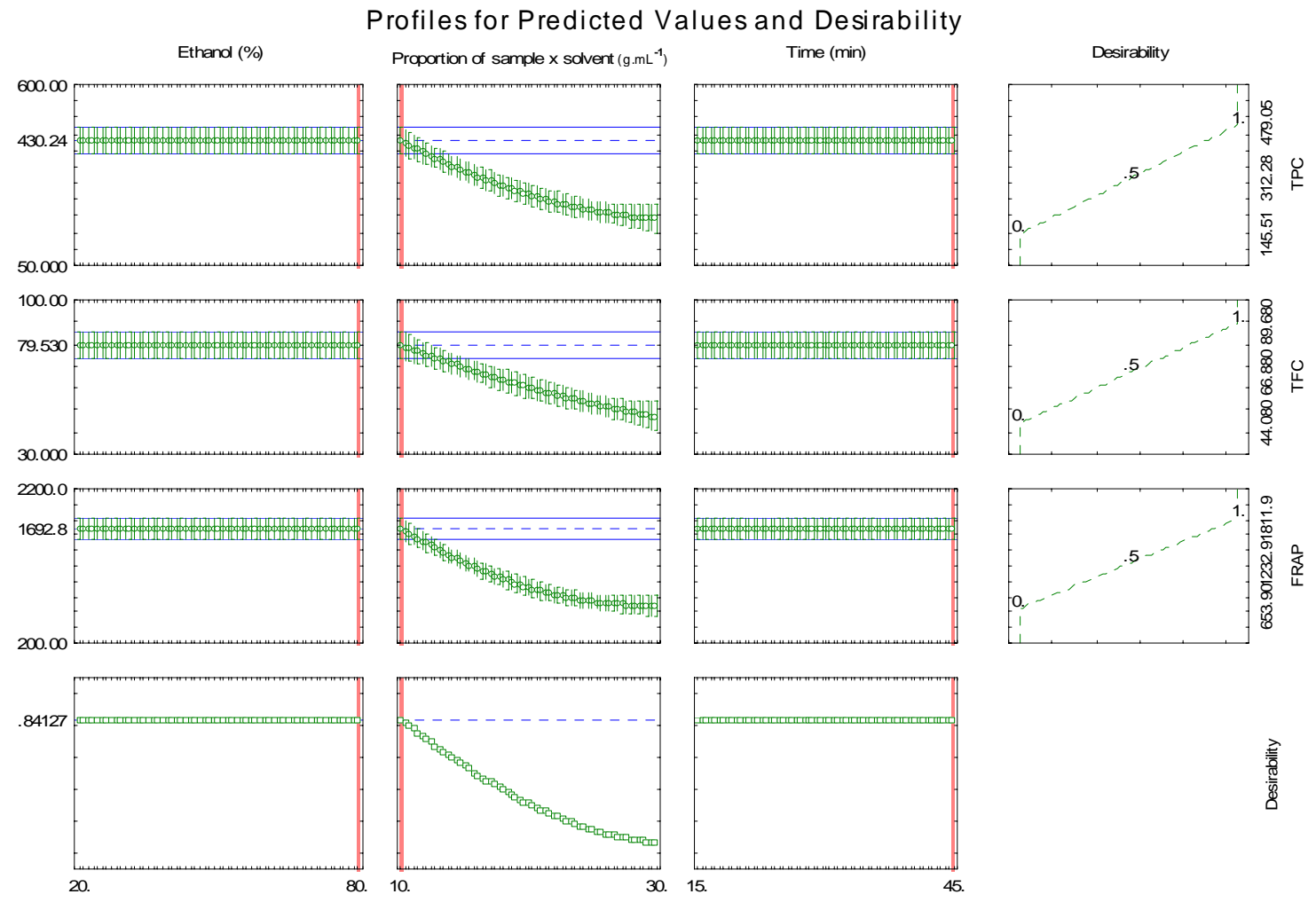

Fig. 4: Optimisation of bioactive compounds from pumpkin peel using the desirability function; TPC: Total Phenolic Compound; TFC: Total Flavonoids Content and FRAP: Ferric Reducing Antioxidant Power

Carvalho et al., 2012). The extracted phytochemicals from pumpkin have shown to present antioxidant, antimicrobial, antiproliferative and hypoglycemic effects (Peschel et al., 2006). Some other investigations showed that a diet rich in pumpkin has pharmacological activity in reducing blood glucose (Adams et al., 2011). After modelling the extraction of total phenolics, total flavonoids and antioxidant activity, a simultaneous optimisation was performed using the desirability function in order to maximise results, as shown in Fig. 4. The optimum values suggested for the extraction, with function desirability of 0.8531 , were: $45 \mathrm{~min}$, ratio of $10 \mathrm{~mL} / \mathrm{g}$ and a solution of solvent containing $80 \%$ ethanol. The extraction conditions that were theoretically suggested were used and the content of TPC determined was $365.76 \pm 46.10 \mathrm{mg} / \mathrm{L}$ of extract and the model provided a value of $389.24 \mathrm{mg} / \mathrm{L}$ (absolute error $=23.48 \mathrm{mg} / \mathrm{L}$ ). The value for antioxidant activity was $1607.07 \pm 32.89 \mathrm{mmol} / \mathrm{L}$ of extract and the model provided a value of $1692.80 \mathrm{mmol} / \mathrm{L}$ (absolute error $=$ $85.73 \mathrm{mg} / \mathrm{L}$ ). The TFC was $74.79 \pm 6.04 \mathrm{mg} / \mathrm{L}$ of extract and the model provided a value of $78.19 \mathrm{mg} / \mathrm{L}$ (absolute error $=3.40 \mathrm{mg} / \mathrm{L}$ ).

All the results found in the external validation of the experiments were within $\pm 95 \%$ of the prediction intervals proposed by the models. The low values of the absolute errors of the experimental results, compared to the predicted results, confirm that the models proposed by RSM are suitable for the prediction of phenolic compounds, total flavonoids and antioxidant activity of pumpkin peel prepared for the extraction of bioactive compounds. 
Knowledge of the nutritional value and bioactive properties of by-products, especially from vegetables, is necessary in order to encourage increased consumption as well as their use as an ingredient in enriched nutritional applications in foods. Bearing in mind that after the removal of the pulp, pumpkin peel is either discarded or used as animal feed and considering its nutritional value, phenolic content and low cost of production, this by-product can be applied for industrial purposes in the food and pharmaceutical industries, for the extraction of target compounds and to complement and supplement human nutrition.

\section{CONCLUSION}

Pumpkin peel flour is a by-product comprising a significant source of bioactive compounds with antioxidant characteristics. The results of this study show that pumpkin peel is also rich in lipids, proteins, minerals, phenolics and flavonoids. RSM was useful in estimating the effect of three independent variables on the extraction of total phenolics, total flavonoids and in vitro antioxidant activity of PPF using ethanol as a green solvent. The TPC was influenced by the solvent used and the solid-liquid ratio of the extraction process, while total flavonoids and FRAP assay only by the solid-liquid ratio. The optimum combinations of the variables to maximise the yield of extraction of bioactive compounds was obtained with a time of 45 min, a ratio of $10 \mathrm{~mL} / \mathrm{g}$ and a solvent solution containing $80 \%$ ethanol. These results reinforce the idea that dried pumpkin peel flour could potentially be a resource for food enrichment, thereby providing extra health benefits to consumers.

\section{ACKNOWLEDGMENT}

The authors are thankful to CNPq and CAPES for financial support, to the State University of Ponta Grossa and the Federal University of Paraná, for the use of the laboratories and to the Q-Sabor company for donating the pumpkin samples. Also, we are grateful to Professor Dr Gilvan Wosiacki (in memoriam) for his contributions in this study.

\section{CONFLICT OF INTEREST}

There are no conflicts of interest.

\section{REFERENCES}

Abou-Elella, F. and R. Mourad, 2015. Anticancer and anti-oxidant potentials of ethanolic extracts of Phoenix dactylifera, Musa acuminata and Cucurbita maxima. Res. J. Pharm. Biol. Chem. Sci., 6(1): 710-720.

Adams, G.G., S. Imran, S. Wang, A. Mohammad, S. Kok and et al., 2011. The hypoglycaemic effect of pumpkins as anti-diabetic and functional medicines. Food Res. Int., 44(4): 862-867.
Akwaowo, E.U., B.A. Ndon and E.U. Etuk, 2000. Minerals and antinutrients in fluted pumpkin (Telfairia occidentalis Hook f.). Food Chem., 70(2): 235-240.

Altemimi, A., D.G. Watson, R. Choudhary, M.R. Dasari and D.A. Lightfoot, 2016. Ultrasound assisted extraction of phenolic compounds from peaches and pumpkins. PLOS ONE, 11(2): 1-20.

Azmir, J., I.S.M. Zaidul, M.M. Rahman, K.M. Sharif, A. Mohamed and et al., 2013. Techniques for extraction of bioactive compounds from plant materials: A review. J. Food Eng., 117(4): 426436.

Barbosa-Pereira, L., A. Bilbao, P. Vilches, I. Angulo, J. Lluis and et al., 2014. Brewery waste as a potential source of phenolic compounds: Optimisation of the extraction process and evaluation of antioxidant and antimicrobial activities. Food Chem., 145: 191197.

Benzie, I.F. and J.J. Strain, 1996. The Ferric Reducing Ability of Plasma (FRAP) as a Measure of "Antioxidant Power": The FRAP Assay. Anal. Biochem., 239(1): 70-76.

de Carvalho, L.M.J., P.B. Gomes, R.L. de Oliveira Godoy, S. Pacheco and et al., 2012. Total carotenoid content, $\alpha$-carotene and $\beta$-carotene, of landrace pumpkins (Cucurbita moschata Duch): A preliminary study. Food Res. Int., 47(2): 337-340.

Casazza, A.A., B. Aliakbarian, S. Mantegna, G. Cravotto and P. Perego, 2010. Extraction of phenolics from Vitis vinifera wastes using nonconventional techniques. J. Food Eng., 100(1): 5055.

Chirinos, R., R. Pedreschi, H. Rogez, Y. Larondelle and D. Campos, 2013. Phenolic compound contents and antioxidant activity in plants with nutritional and/or medicinal properties from the Peruvian Andean region. Ind. Crops Prod., 47: 145-152.

Derringer, G. and R. Suich, 1980. Simultaneous optimization of several response variables. J. Qual. Technol., 12(4): 214-219.

Elsorady, M.E.I. and S.E. Ali, 2018. Antioxidant activity of roasted and unroasted peanut skin extracts. Int. Food Res. J., 25(1): 43-50.

Fertonani, H.C.R., A. Scabio, E.B.B. Carneiro, M.H.C. Schemim, A. Nogueira and G. Wosiacki, 2009. Extraction model of low methoxyl pectin from apple pomace effects of acid concentration and time on the process and the product. Brazilian Arch. Biol. Technol., 52(1): 177-185.

González-Montelongo, R., M. Gloria Lobo and M. González, 2010. Antioxidant activity in banana peel extracts: Testing extraction conditions and related bioactive compounds. Food Chem., 119(3): 1030-1039.

Guiné, R.P.F., S. Pinho and M.J. Barroca, 2011. Study of the convective drying of pumpkin (Cucurbita maxima). Food Bioprod. Process., 89(4): 422-428. 
Ito, V.C., A. Alberti, S. Avila, M. Spoto, A. Nogueira and G. Wosiacki, 2016. Effects of gamma radiation on the phenolic compounds and in vitro antioxidant activity of apple pomace flour during storage using multivariate statistical techniques. Innov. Food Sci. Emerg. Technol., 33: 251-259.

John, B., C.T. Sulaiman, S. George and V.R.K. Reddy, 2014. Total phenolics and flavonoids in selected medicinal plants from Kerala. Int. J. Pharm. Pharm. Sci., 6(1): 406-408.

Khajeh, M., 2011. Response surface modelling of lead pre-concentration from food samples by miniaturised homogenous liquid-liquid solvent extraction: Box-Behnken design. Food Chem., 129(4): 1832-1838.

Košt’álová, Z., M. Aguedo and Z. Hromádková, 2016. Microwave-assisted extraction of pectin from unutilized pumpkin biomass. Chem. Eng. Process., 102: 9-15.

Krishnaiah, D., R. Sarbatly and R. Nithyanandam, 2011. A review of the antioxidant potential of medicinal plant species. Food Bioprod. Process., 89(3): 217-233.

Maizura, M., A. Aminah and W.M. Wan Aida, 2011. Total phenolic content and antioxidant activity of kesum (Polygonum minus), ginger (Zingiber officinale) and turmeric (Curcuma longa) extract. Int. Food Res. J., 18: 529-534.

Maran, J.P., V. Mekala and S. Manikandan, 2013. Modeling and optimization of ultrasound-assisted extraction of polysaccharide from Cucurbita moschata. Carbohydr. Polym., 92(2): 2018-2026.

Maran, J.P., S. Manikandan, V. Nivetha and R. Dinesh, 2017. Ultrasound assisted extraction of bioactive compounds from Nephelium lappaceum L. fruit peel using central composite face centered response surface design. Arab. J. Chem., 10: S1145-S1157.

Mirhosseini, H., N. Farhana, A. Rashid, B.T. Amid, K.W. Cheong and et al., 2015. Effect of partial replacement of corn flour with durian seed flour and pumpkin flour on cooking yield, texture properties and sensory attributes of gluten free pasta. LWT-Food Sci. Technol., 63(1): 184-190.

Morelli, L.L.L. and M.A. Prado, 2012. Extraction optimization for antioxidant phenolic compounds in red grape jam using ultrasound with a response surface methodology. Ultrason. Sonochem. 19(6): 1144-1149.

Peschel, W., F. Sánchez-Rabaneda, W. Diekmann, A. Plescher, I. Gartzía and et al., 2006. An industrial approach in the search of natural antioxidants from vegetable and fruit wastes. Food Chem., 97(1): 137-150.

Ponka, R., A.A. Bouba, E. Fokou, S.T. Tambe, E. Beaucher and et al., 2015. Protein, mineral and amino acid content of some Cameroonian traditional dishes prepared from pumpkin (Cucurbita maxima Duch.). J. Food Compos. Anal., 43: 169-174.
Ptichkina, N.M., O.A. Markina and G.N. Rumyantseva, 2008. Pectin extraction from pumpkin with the aid of microbial enzymes. Food Hydrocoll., 22(1): 192-195.

Rezig, L., M. Chouaibi, K. Msaada and S. Hamdi, 2012. Chemical composition and profile characterisation of pumpkin (Cucurbita maxima) seed oil. Ind. Crops Prod., 37(1): 82-87.

Rubio-Senent, F., G. Rodríguez-Gutiérrez, A. LamaMuñoz and J. Fernández-Bolaños, 2013. Phenolic extract obtained from steam-treated olive oil waste: Characterization and antioxidant activity. LWTFood Sci. Technol., 54(1): 114-124.

Santos, D.T. and M.A.A. Meireles, 2011. Optimization of bioactive compounds extraction from jabuticaba (Myrciaria cauliflora) skins assisted by high pressure CO2. Innov. Food Sci. Emerg. Technol., 12(3): 398-406.

Sarikurkcu, C., K. Arisoy, B. Tepe, A. Cakir, G. Abali and E. Mete, 2009. Studies on the antioxidant activity of essential oil and different solvent extracts of Vitex agnus castus L. fruits from Turkey. Food Chem. Toxicol., 47(10): 2479-2483.

Sarkis, J.R., I. Michel, I.C. Tessaro and L.D.F. Marczak, 2014. Optimization of phenolics extraction from sesame seed cake. Sep. Purif. Technol., 122: 506-514.

Shi, X., H. Wu, J. Shi, S.J. Xue, D. Wang, W. Wang and et al., 2013. Effect of modifier on the composition and antioxidant activity of carotenoid extracts from pumpkin (Cucurbita maxima) by supercritical $\mathrm{CO}_{2}$. LWT-Food Sci. Technol., 51(2): 433-440.

Singleton, V.L. and J.A. Rossi, 1965. Colorimetry of total phenolics with phosphotungstic acid reagents. Am. J. Enol. Vitic., 16(3): 2349-2351.

Turumtay, E.A., F. İslamoğlu, D. Çavuş, H. Şahin, H. Turumtay and B. Vanholme, 2014. Correlation between phenolic compounds and antioxidant activity of Anzer tea (Thymus praecox Opiz subsp. caucasicus var. caucasicus). Ind. Crops Prod., 52: 687-694.

Wu, T., J. Yan, R. Liu, M.F. Marcone, H.A. Aisa and R. Tsao, 2012. Optimization of microwave-assisted extraction of phenolics from potato and its downstream waste using orthogonal array design. Food Chem., 133(4): 1292-1298.

Zheng, X., F. Yin, C. Liu and X. Xu, 2011. Effect of process parameters of microwave assisted extraction (MAE) on polysaccharides yield from pumpkin. J. Northeast Agric. Univ. Eng. Edn., 18(2): 79-86.

Zhishen, J., T. Mengcheng and W. Jianming, 1999. The determination of flavonoid contents in mulberry and their scavenging effects on superoxide radicals. Food Chem., 64(4): 555-559. 